\title{
Pre-crash performance of collision mitigation and avoidance systems - results from the ASSESS project
}

\author{
Andrés Aparicio*, Sébastien Baurès, Jordi Bargalló, Applus IDIADA Group, Spain \\ Carmen Rodarius, John Vissers, TNO, The Netherlands \\ Oliver Bartels, Patrick Seiniger, Bundesanstalt für Straßenwesen (BASt), Germany \\ Paul Lemmen, Humanetics Europe GmbH, The Netherlands \\ Thomas Unselt, Daimler AG, Germany \\ Maminirina Ranovona, Tatsuhiro Okawa, TOYOTA MOTOR EUROPE NV/SA, Belgium \\ Swen Schaub, TRW Automotive GmbH \\ *Polígon l'Albornar s/n, PO box 20 \\ Santa Oliva, Tarragona, E-43710, SPAIN \\ Phone: +34 977166 029, E-mail: aaparicio@idiada.com
}

\begin{abstract}
Integrated vehicle safety systems that combine elements from primary and secondary safety have a high potential to improve vehicle safety, due to their ability to influence crash conditions and/or to adapt to these crash conditions. So far no standard evaluation procedures have been developed and implemented.

The main goal of the ASSESS project is to develop harmonized and standardized assessment procedures for related collision mitigation and avoidance systems. Procedures are developed for:

- Driver behavior evaluation

- Pre-crash system performance evaluation

- Crash performance evaluation

- Socio-economic assessment

This paper presents the activities related to the "Pre-Crash evaluation". The objective is to provide a tool box for the specific evaluation of the pre-crash performance of collision mitigation and avoidance systems and their contribution to the overall system performance.
\end{abstract}

Topics/Active \& Passive Safety Systems, Driver-vehicle Systems \& Driving Simulator

\section{INTRODUCTION}

In order to have a wide spread impact on safety, a test procedure for driving assistance systems has to be directly linked to the effectiveness of these systems. The paper describes how the complete test procedure has been developed, including the derivation of 'Test scenarios' from 'Accident scenarios', the development of a 'Test target' representing a full 3D vehicle suitable for 'car to car' testing and the definition of the most relevant 'Key performance indicators'.

Unlike other approaches, the ASSESS test procedures do not only test full autonomous braking but also incorporate driver reaction. Hence, also warning functions can be evaluated.

This test procedure was evaluated in three different test laboratories, each using a different methodology to move the so called target vehicle. Challenges faced in each test setup will be discussed.

Besides the definition of the test procedure, an important result is also the definition of appropriate accuracies, needed to achieve a high reproducibility, repeatability and robustness.

\section{SCENARIOS}

Based on available accident data within the consortium (including GIDAS, STATS -19 and national data from different countries), four groups of accident scenarios and parameters have been identified:

- Rear-end collisions in longitudinal traffic

- Intersection with cross-traffic accidents

- Collisions with oncoming traffic

- Cut-in maneuvers in longitudinal and oncoming traffic

All these accident scenarios have been prioritized and for the most relevant ones adequate test scenarios have been derived, However, intersections and oncoming traffic, as well as cut-in with oncoming traffic cannot be addressed by systems currently available in the market and/or to appear in the next years. For this reason, the actually executed test maneuvers were reduced to rear-end collisions in longitudinal traffic. A detailed description is given in [1], [2], [3] and [4].

It is important to distinguish accident scenarios and test scenarios. Accident scenarios describe those real life situations that are most relevant and typical real traffic accidents, while test scenarios name the abstract 
conversion of the accident scenarios into a standardized, repeatable, reproducible test laboratory situation. The final test scenarios are:

- $\quad$ Stationary Target Vehicle (TV, the test target ) approached by the Subject Vehicle (SV, the vehicle under test ) at constant speed (50 and $80 \mathrm{~km} / \mathrm{h})$.

- Slow TV (10 km/h constant speed) approached by faster $\mathrm{SV}(50 \mathrm{~km} / \mathrm{h}$ constant speed $)$.

- TV and SV driving at constant speed $(50 \mathrm{~km} / \mathrm{h}$, with initial heading distance of $14 \mathrm{~m}$ ) and TV braking (with 4 and $7 \mathrm{~m} / \mathrm{s}^{2}$ deceleration).

The runs were carried out usually with an overlap of $100 \%$, but some of them were also performed with an overlap of $50 \%$.

There were also scenarios defined with a TV driving at $20 \mathrm{~km} / \mathrm{h}$ and an approaching SV at $100 \mathrm{~km} / \mathrm{h}$. Since there is not enough data for statistical analysis, these scenarios are also not considered further here.

\subsection{Test method requirements}

The objective is to improve road safety. Therefore, the procedure must deliver results that match the behavior of the vehicle under test with the real world.

The test method presented here is intended for both consumer tests (such as Euro NCAP), as well as for vehicle technical standards (such UN ECE). The primary goal is to be able to determine test results that are objective, reproducible and repeatable.

Moreover, there are other boundary conditions. For example, it is necessary to keep the test time and test costs under control. It also must be possible to test the behavior of the vehicle with a black box approach, without access to internal parameters or specifications of the manufacturer (although certain vehicles present some issues, as they need to be reset when the AEB is activated repeatedly). And finally, tests and results have to be transmitted to the consumers in a comprehensive but understandable way.

\subsection{Consideration of driver behavior}

In order to take into account the behavior of the driver during emergency braking, ASSESS implemented several activities for determining driver reaction time [5]. A sample of real drivers was requested to drive in rear-end accident scenarios in driving simulators in order to derive these parameters.

From these tests, a constant force rate of $300 \mathrm{~N} / \mathrm{s}$ up to a maximum brake pedal force of $360 \mathrm{~N}$ was defined as average driver's action over the brake pedal and a driver's reaction time of 1.2 seconds to visual and / or audible warning. The transferability of these results to other vehicles cannot be guaranteed. However, the value of the reaction time is consistent with [6].

\subsection{Braking and warning times}

The mechanics of the braking process - particularly with regard to emergency braking systems - is derived from the report from Winner [7].
The common measurement for assessing the risk situation is the so called Time-to-collision (TTC). This is the time that would remain until the collision point, assuming a uniform motion of the SV and TV:

$$
T T C=\frac{\text { relative distance }}{\text { relative speed }}
$$

In order to better understand accident avoidance, several kinematics calculations can be implemented with this value. Some remarks follow.

For an initial situation with full overlap of two vehicles and a vehicle width of 2 meters in a imminent rear-end condition, the minimum escape time is approximately $0.6 \mathrm{~s}$. The vehicle response delay can be considered by adding $0.1 \mathrm{~s}$. These times are not reached by ordinary drivers in general. Winner [7] gives values of 1 to $1.6 \mathrm{~s}$ for normal evasive actions.

Suitable warning times should then be placed so that the driver can still avoid the accident and that the warning is not triggered too early. It should be noted that (already relatively rare) false alerts, adversely affects the confidence of the driver into the system ([8], p.7). A warning should be triggered so that the accident can be avoided with the usual response time and delay ( $1 \mathrm{~s}$ driver reaction + the time of the evasive maneuver).

The appropriate time for an autonomous braking intervention can also be derived with similar concepts, but is much more limited by legal constraints (the Vienna Convention, product liability issues) and other associated technical difficulties (recognition reliability). For example, systems only initiate a full intervention when the accident is not avoidable [9].

\subsection{Derivation of key performance indicators}

The measurements during the tests are mainly accelerations, velocities and positions of the SV and TV. Additionally, the trigger time of additional safety feature, e.g. reversible belt pretensioners was recorded, see also [17]. For the evaluation of individual vehicles and the statistical analysis of reproducibility and repeatability of the test procedure, however, discrete parameters are required:

- The TTC value at the time of the first warning defines the warning behavior of the SV.

- The start of braking maneuver is represented by the TTC at the time when the SV exceeds the threshold of $0.1 \mathrm{~m} / \mathrm{s}^{2}$.

- The speed reduction is the difference of the initial closing speed of the vehicles when TTC is $3 \mathrm{~s}$ and the closing speed at impact. Closing speed refers here to relative speed between SV and TV.

Based on these characteristics, a total of more than 300 experiments have been statistically analyzed to obtain a statement about the validity.

\subsection{Validation criteria}

Realism of the test procedure

An autonomous braking intervention can be 
expected when the safety system detects with relatively high degree of certainty an unavoidable collision. For reasons of product safety and liability this requires a high level of confidence [10].

A warning to the driver will certainly require a lower confidence threshold, but for reasons of product acceptance, the vehicle manufacturer has an interest in keeping the number of false warnings as small as possible. Thus, timing for warning was selected as validation criterion for transferability of the results to reality.

\section{Repeatability}

Repeatability can be validated if results within a test house have a small scatter. For this, a classical mean analysis is not possible, since the real expected value is not known. The repeatability is therefore considered initially to be sufficient if the standard deviation is significantly smaller than $10 \%$ of the mean value. A deeper analysis will be prepared by project partners at the end of the ASSESS project.

\section{Reproducibility}

As part of the ASSESS project, the defined test procedures have been implemented in three different test houses with very different test tools. If it is possible to show that the results (warning time points, braking points in time, speed reduction) between the three testing institutes are comparable, the reproducibility of the test method can be validated.

\section{TEST TOOLS}

\subsection{Measurement and control}

The test vehicles were equipped with different measurement equipment to accurately determine the position and velocity. These were differential GPS combined with inertial platforms (BASt, IDIADA) and high-precision in-door position sensor (TNO). When needed, data obtained in SV and TV could be synchronized by the use of GPS time signal.

Relative position of the vehicles (longitudinal and lateral) was controlled by human drivers (BASt), by robots (IDIADA) or by a guided system (TNO).

The contact between SV and TV (to determine impact point in time, if occurred) was determined by contact sensors (BASt, IDIADA) or direct position determination (TNO).

The detection of the acoustic warning signal was done with microphones and frequency filters. These allowed the real-time detection of the warning and the triggering of the driver reaction.

The driver reaction (1.2 s after the driver warning) was applied in all test houses with a brake robot which actuated over the brake pedal.

\subsection{Test targets}

ASSESSOR test target

The test target developed within the ASSESS project is the ASSESSOR [11]. It has an internal radar reflector made of metallic foil and its radar-reflecting characteristics represent a typical compact car [1].
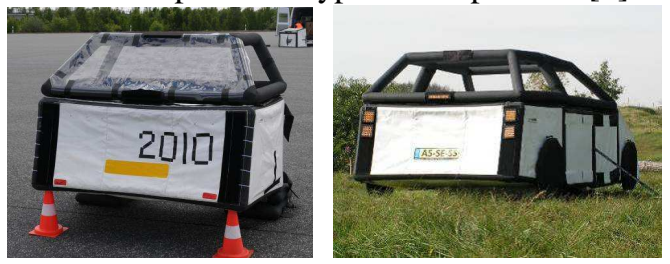

Fig. 1 ASSESSOR target, left: rear end only without lights, right: full test target without rear window

This target object is able to withstand impacts up to $80 \mathrm{~km} / \mathrm{h}$-depending on the mass of the propulsion system- with good levels of crash forgivingness.

\section{ADAC test target}

The ADAC-target is optimized for good detectability and is commercially available. In combination with the ADAC propulsion system, it is able to withstand impacts up to $50 \mathrm{~km} / \mathrm{h}$ relative speeds, without any significant damage to the SV (see Figure 5).

\section{Reference vehicle}

In order to validate the test targets, a VW Passat (model year 2011) was used as a reference. Several approaching tests were executed. For safety reasons, the tests were terminated when the warning signal was issued. The validation process compared the warning times obtained with the different targets.

\subsection{Propulsion systems}

Remote Kart System (BASt)

BASt has developed its own propulsion system for test targets. It is based in a kart concept and its name is MARVIN (Motorized Autonomous Research Vehicle for INnovations).

Top speed is over $80 \mathrm{~km} / \mathrm{h}$, with a maximum deceleration of $7 \mathrm{~m} / \mathrm{s}^{2}$. The total mass is $250 \mathrm{~kg}$ including the test target (ASSESSOR). The speed of the kart is controlled by a closed-loop controller on-board and braking and steering by a remote control commanded by an operator outside the vehicle.

During the tests, the system withstood impacts up to $50 \mathrm{~km} / \mathrm{h}$ without significant damage to the SV. A detailed description is given in [12] and [13].

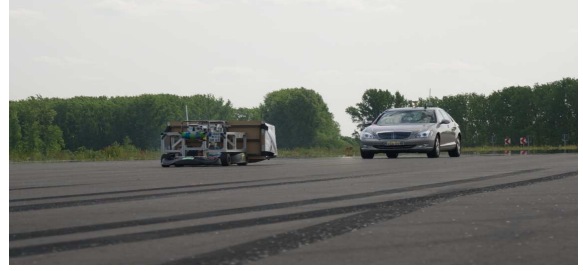

Fig. 2 BASt MARVIN kart with the ASSESSOR

The tests implemented for this analysis were done in the proving grounds of the RWTH Aachen in Aldenhoven and in an air base rented by BASt.

The controllability of the system is $0.5 \mathrm{~km} / \mathrm{h}$ and \pm 
$30 \mathrm{~cm}$ in position.

\section{Rabbit vehicle (IDIADA)}

IDIADA used a rabbit vehicle concept, which consists of a car carrying a test target hold from a crane. IDIADA used the full ASSESSOR. This is mounted on a trolley, which is initially connected with an electromagnet to a crane. In case of collision, the solenoid and the whole target are released.

The trolley is shielded with radar absorbing material, in order to do not interfere with the radar system of the SV. In both vehicles, a complete set of driving robots are used to precisely control the trajectories and relative positions of both vehicles.

The running speed of the rabbit vehicle can be specified very precisely. A lateral offset of a few centimeters can be achieved.

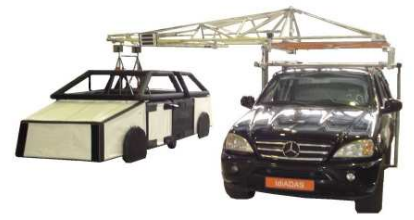

Fig. 3 IDIADA rabbit vehicle

$$
\text { VeHIL (TNO) }
$$

The test laboratory VeHIL (Vehicle Hardware in the Loop) consists of a chassis dynamometer where the SV is mounted and a support system (trolley) on which the TV is mounted (rail guided or robotic vehicles). VehIL works with the principle of relative motions, which means that instead of having both, SV and TV moving, the SV is stationary, although driving on the chassis dynamometer, and the TV moves relatively towards the SV. The dynamometer is adjustable so that the braking performance matches the vehicle's performance on real roads. The system is located in a hall with inside dimensions of $200 \mathrm{~m} x 40 \mathrm{~m}$. The speed of the test vehicle is processed real time by a simulation unit and translated to the real world situation. From there, this unit feeds back all necessary information to the pre- crash test system (PCTS) resulting in an adaption of the TV's speed according to the actions taken by the car on the roller bench. .

As part of the ASSESS project the PCTS was implemented. This allowed tests with relative speeds up to $80 \mathrm{~km} / \mathrm{h}$ and tests up to TTC $=0 \mathrm{~s}$.

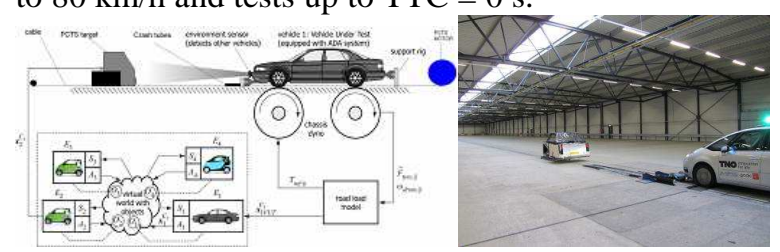

Fig. 4 VeHIL test bench concept with PCTS

Principal advantages of this test system are the high repeatability of the system, the independence to weather influences and the use of relative movements that allow also safe testing of high speeds. For high relative speeds, the system can be adjusted with dampers or crash tubes that absorb part of the impact, thus reducing the impact severity for SV and TV and allowing testing also at high relative speeds with only small risk of damage to the TV and SV.

\section{Rail system (ADAC)}

The motion system consists of a running trailer made up of rails. These rails carry a sled which holds the test target. When the target is impacted, it can slide over the rails.

Static tests were always performed with the rail system, but without any towing vehicle.

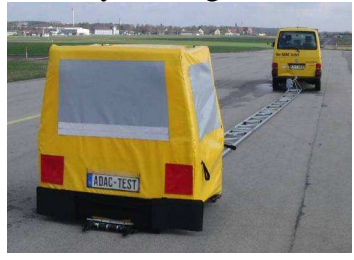

Fig. 5 ADAC rail system and test target (Source: ADAC)

The ADAC test system can be moved with a maximum speed of $80 \mathrm{~km} / \mathrm{h}$ and a maximum impact speed of $50 \mathrm{~km} / \mathrm{h}$. The test system can be decelerated up to $6.5 \mathrm{~m} / \mathrm{s}^{2}$. The speed of the towing vehicle can be adjusted by experienced drivers with $1 \mathrm{~km} / \mathrm{h}$ accuracy. A lateral offset of approximately $\pm 30 \mathrm{~cm}$ is reached.

The main limitation of this test setup is that it does not allow tests involving lane changes or with a certain overlap, because there could be an radar interference from the rail system.

\subsection{Test vehicles}

Various SV were available to evaluate the proposed test procedures in the test labs. The two vehicles that were tested in all the test institutes use only radar sensors in various configurations. A detailed description of system properties is given in the next table.

Table 1 Properties of the tested vehicles

\begin{tabular}{|c|c|c|}
\hline & Vehicle A & Vehicle B \\
\hline System & \multicolumn{2}{|c|}{$\begin{array}{l}\text { Radar-based system. Autonomous braking if a } \\
\text { collision is unavoidable, brake assist different } \\
\text { thresholds depending on the detected target object }\end{array}$} \\
\hline Warning & $\begin{array}{l}\text { Optical and acoustic } \\
\text { warning at TTC }=2.6 \mathrm{~s}\end{array}$ & $\begin{array}{l}\text { Visual and audible } \\
\text { warning when TTC 2-3 s }\end{array}$ \\
\hline $\begin{array}{l}\text { Autonomou } \\
\text { s actions }\end{array}$ & $\begin{array}{l}\text { If no reaction by the } \\
\text { driver after a warning by } \\
\text { the driver, two-stage } \\
\text { automatic braking at } \\
\text { TTC }=1.6 \mathrm{~s} \text { (partial } \\
\text { braking), TTC }=0.6 \mathrm{~s} \\
\text { (full braking) }\end{array}$ & $\begin{array}{l}\text { If no reaction by the } \\
\text { driver, different levels of } \\
\text { autonomous } \\
\text { braking. Delays and } \\
\text { thresholds unpublished. }\end{array}$ \\
\hline Sensors & $\begin{array}{l}\text { Short-range radar }(30 \mathrm{~m}), \\
\text { medium-range radar }(60 \\
\text { m), long-range radar } \\
(200 \mathrm{~m}) \text {, camera }\end{array}$ & $\begin{array}{l}\text { Long-range radar (range> } \\
150 \mathrm{~m} \text { ) }\end{array}$ \\
\hline
\end{tabular}

An overview of the tested combinations (TV and $\mathrm{SV}$ ) is presented in the next table.

Table 2 Tested combinations of TV and SV 


\begin{tabular}{cclcc}
\hline No & \multicolumn{1}{c}{ Target } & $\begin{array}{c}\text { Propulsión } \\
\text { system }\end{array}$ & $\begin{array}{c}\text { Vehic } \\
\text { le }\end{array}$ & $\begin{array}{c}\text { Driver } \\
\text { reaction }\end{array}$ \\
\hline $\mathbf{1}$ & ASSESSOR & MARVIN Kart & $\mathrm{A}$ & Yes / No \\
\hline $\mathbf{2}$ & ASSESSOR & MARVIN Kart & $\mathrm{B}$ & Yes / No \\
\hline $\mathbf{3}$ & ASSESSOR & VeHIL & $\mathrm{A}$ & Yes / No \\
\hline $\mathbf{4}$ & ASSESSOR & VeHIL & $\mathrm{B}$ & Yes / No \\
\hline $\mathbf{5}$ & ASSESSOR & Rabbit vehicle & $\mathrm{A}$ & Yes / No \\
\hline $\mathbf{6}$ & ASSESSOR & Rabbit Vehicle & $\mathrm{B}$ & Yes / No \\
\hline $\mathbf{7}$ & ADAC & Trailer & $\mathrm{A}$ & No \\
\hline $\mathbf{8}$ & VW Passat & - & $\mathrm{A}$ & No \\
\hline
\end{tabular}

\section{RESULTS}

\subsection{Overall results}

The following plot shows an example of the measurements obtained in several test runs.
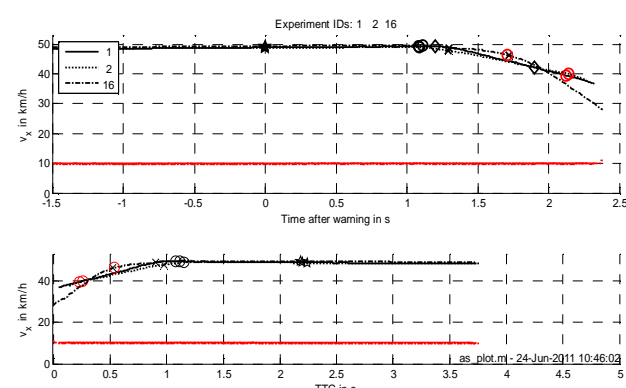

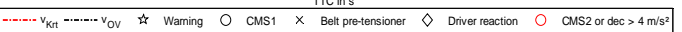

Fig. 6 Plot of three measurements: vehicle A at $50 \mathrm{~km} / \mathrm{h}$ and MARVIN at $10 \mathrm{~km} / \mathrm{h}$, with no driver reaction, reaction after $1.2 \mathrm{~s}$, and reaction after $1.7 \mathrm{~s}$, shown values are for warning, braking and trigger of the reversible pre-tensioners

An overview of the results for selected scenarios is shown in the next table (full analysis in [13]).

Table 3 Mean values of parameters for selected scenarios (separated by vehicle)

\begin{tabular}{|c|c|c|c|c|c|c|c|c|}
\hline \multirow[t]{2}{*}{ Scenario } & \multicolumn{2}{|c|}{$\begin{array}{l}\text { No of } \\
\text { tests }\end{array}$} & \multicolumn{2}{|c|}{$\begin{array}{c}\text { Speed } \\
\text { reduction }\end{array}$} & \multicolumn{2}{|c|}{$\begin{array}{c}\text { TTC at } \\
\text { warning }\end{array}$} & \multicolumn{2}{|c|}{$\begin{array}{l}\text { TTC at } \\
\text { braking }\end{array}$} \\
\hline & A & B & A & B & A & B & A & B \\
\hline $\begin{array}{l}50-10 \text { wo } \\
\text { reaction }\end{array}$ & 42 & 24 & 16,36 & 10,48 & 2,17 & 2,79 & 1,14 & 0,80 \\
\hline $\begin{array}{l}50-10 \text { with } \\
1,2 \text { s reaction }\end{array}$ & 21 & 19 & 38,77 & 19,13 & 2,11 & 2,82 & 1,05 & 0,66 \\
\hline $\begin{array}{l}50-0 \text { wo } \\
\text { reaction }\end{array}$ & 17 & 25 & 12,81 & 6,37 & 2,08 & 0,00 & 1,08 & 0,60 \\
\hline $\begin{array}{l}50-0 \text { with } 1,2 \mathrm{~s} \\
\text { reaction }\end{array}$ & 13 & 8 & 28,66 & 7,92 & 2,03 & 0,13 & 0,87 & 0,60 \\
\hline $\begin{array}{l}80-0 \text { wo } \\
\text { reaction }\end{array}$ & 1 & 0 & 0,00 & 0,00 & 1,05 & 0,00 & 0,00 & 0,00 \\
\hline $\begin{array}{l}80-0 \text { with } 1,2 \mathrm{~s} \\
\text { reaction }\end{array}$ & 2 & 0 & 27,47 & 0,00 & 1,92 & 0,00 & 0,81 & 0,00 \\
\hline Total & 96 & 76 & & & & & & \\
\hline
\end{tabular}

\subsection{Applicability to reality}

The considerations in [7] and in Section 2.5 can be further developed in order to define an optimum area of feasibility where a warning can lead to avoidance of the accident (either by evasion or braking action initiated by the driver). This area is marked in green in the graph below. Additionally, the measurement results of warning times (TTC) are plotted as function of differential speed.

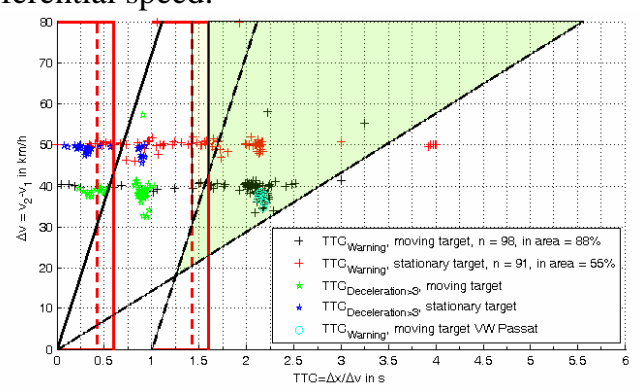

Fig. 7 Range of expected warnings compared to measured warnings

The vast majority of warnings (both vehicles, all targets) is within the expected range (as defined in [16]). In the case of the moving $\mathrm{TV}$, in $88 \%$ of the runs a warning was initiated. In the stationary case, the rate is significantly lower. This is consistent with the experience that the identification of a stationary target is much challenging, particularly for systems using only radar sensors [14].

The warnings obtained with a real vehicle are comparable to the warnings on the target objects.

Additionally, it is found that braking takes place at the earliest at a TTC of about $1 \mathrm{~s}$. The accident at this time in practice is no longer avoidable [7].

The measurement results obtained with the developed test procedures cover correctly the real vehicle performance and the expected values. This validates the test method including stationary and moving TV and the use of autonomous actions of the vehicles and driver reactions.

\subsection{Repeatability and reproducibility}

An overview of the results of various test houses and vehicles is presented in the next figures.
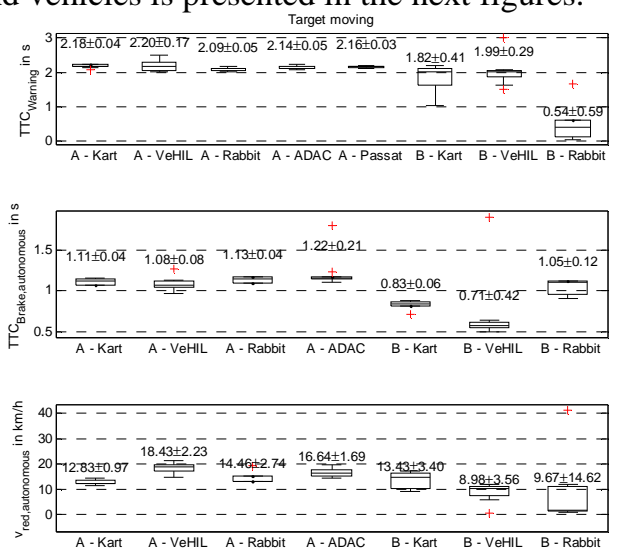

Fig. 8 Results of the moving TV with mean and standard deviation (not simulated driver's reaction)

The results with a moving TV (scenario: SV 50 $\mathrm{km} / \mathrm{h}$, TV $10 \mathrm{~km} / \mathrm{h}$, no driver's reaction, no offset) show a good comparability for warning and braking time for all test houses with vehicle A. The scatter, both within the test institute (= repeatability), and among different 
testing bodies (= reproducibility) are small and this applies also to the reduction in speed.

The speed reduction in the VeHIL and ADAC system is slightly higher than with MARVIN and rabbit vehicles. Possible explanations for this are:

- The 'better' results were obtained at a later stage in the project - and it was already known that a calibration of the radar from vehicle $\mathrm{A}$ should be made after each attempt.

- It is also known that the ASSESSOR begins to flutter slightly in crosswinds. This flutter does not occur naturally in a hall (VeHIL) and is not observed for the ADAC test target

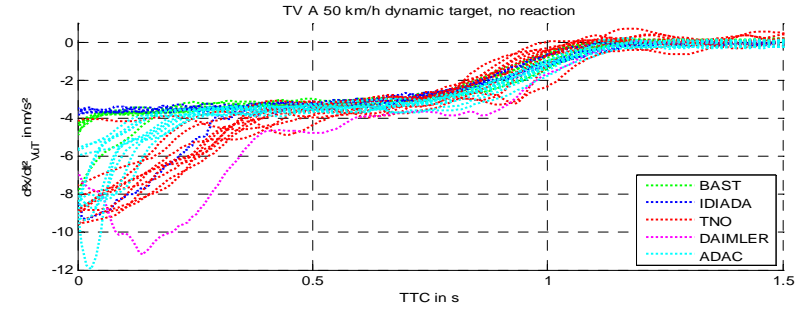

Fig. 9 Deceleration as a function of TTC for vehicle A, separated by test institutes (for comparison, tests executed by Daimler are also included)

The repeatability of the measurements with stationary TV is shown in the next figure. Results were less repeatable for vehicle B. Since this is not the case for all test institutes and not for vehicle $\mathrm{A}$, it is assumed that this is not influenced by the motion system. More likely is, that the ASSESSOR target was difficult to detect by vehicle B under some circumstances.
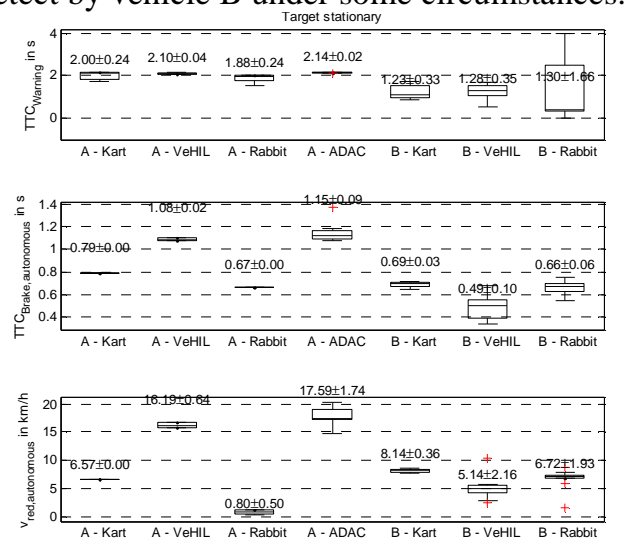

Fig. 10: Results for stationary TV with the mean and standard deviation (not simulated driver's reaction)

\subsection{Influence of driver reaction in repeatability and reproducibility}

It has been checked that in order to have a repeatable and reproducible simulation of the driver's reaction, it is important to implement a good control of the actuator and limit elasticities of the connection.

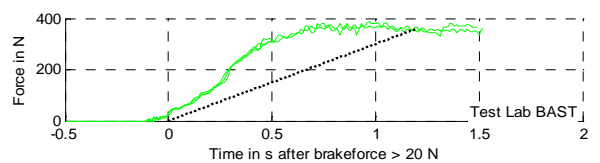

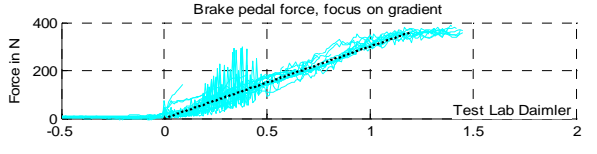

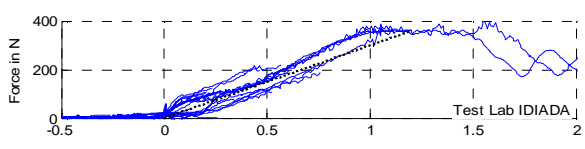

Fig. 11 Brake force during the tests with driver reaction

Despite the difficulties to implement a repeatable driver reaction, the consortium concludes that a simulated driver's reaction is important for the assessment of the safety effect, as it also allows the evaluation of brake assistance.

An alternative approach is described in [15, page 26], but it relies in the tuning of the force control based on the vehicle specific performance.

\section{CONCLUSIONS}

\subsection{Validation of the test procedure}

The presented results show that the proposed test method is suitable for the assessment of the performance of a pre-crash braking system when facing a moving target at constant speed. The measurement of the performance against a stationary TV turned out to be more difficult. However, by using an improved test target more consistent results are expected.

One of the key factors affecting the test results seems to be the target object itself, especially because a good balance between robust detectability for different sensing technologies (e.g. radar, video, etc.), flexible usage for all defined scenarios, as well as crashability up to high $\Delta \mathrm{v}$ without damage to the SV.

On the other side, different propulsion systems and laboratory set-ups were used comparatively. The results proof, that the proposed assessment methodology can work with various laboratory set-ups and therefore is well suited for widespread application.

Furthermore, the study shows that it is very important to implement driver reaction, in order to observe the full benefit of the integrated safety system.

\subsection{Test requirements}

For the test scenarios with a constant speed TV, variables to control are:

- $\quad$ Speed of the TV

- $\quad$ Speed of the SV (including brake system operations / simulated driver's reaction)

- Relative distance (longitudinal and lateral) and heading angle between SV and TV

- Brake pedal control, in order to simulate driver reaction

Speed value of the TV and SV could easily be controlled within the range of $\pm 1 \mathrm{~km} / \mathrm{h}$.

The measured TTC values between the test institutes are well comparable. The achieved accuracies (s.d. of about $2 \%$ ) are considered to be sufficient. 
Scatter in the measured speed reduction is about an order of magnitude, depending on the test institute. These comparatively high variances indicate that the final measured speed reduction is highly sensitive to all test parameters. It has to be noted that for the tests for one vehicle the scatter was significantly lower than for the other vehicle, where also different stages of ASSESSOR were used. After further improvements to the target, this point should be evaluated again.

The maximum lateral alignment during the experiments was in the range of a few $\mathrm{cm}$ (TNO VeHIL, IDIADA rabbit vehicle) or in the area $\pm 30 \mathrm{~cm}$ (BASt Kart, ADAC motor system). However, no significant difference in results between these two groups can determined. The influence of the lateral distance (if they are in the range $\pm 30 \mathrm{~cm}$ ) is therefore negligible.

This is consistent with the theoretical analysis of expected system performance for $50 \%$ overlap and $100 \%$ overlap: since the point of no return for steering evasion only moves $150 \mathrm{~ms}$ in time, robust AEB systems should not change their braking strategy for offset situations. This will certainly be different for low overlap (e.g. $5 \%$ ).

In principle, the speeds should be kept constant prior to the start for a few seconds. In the ASSESS experiments, a period of at least $3 \mathrm{~s}$ was proposed.

These are the suggested repeatability values:

- $\quad$ Speed $\pm 1 \mathrm{~km} / \mathrm{h}$

- Lateral distance $\quad \pm 30 \mathrm{~cm}$

- Beginning of the test $\gg>3 \mathrm{~s}$ TTC

\section{ACKONLEDGEMENT}

This paper summarizes the latest results corresponding to the pre-crash performance of the European project ASSESS (Assessment of Integrated Vehicle Safety Systems for improved vehicle safety, EC grant agreement no. 233942).

\section{REFERENCES}

[1] Oliver Bartels, Tobias Langner, Adrés Aparicio, Carmen Rodarius, Paul Lemmen: ASSESS D4.1 Action Plan Pre-Crash Evaluation. Bergisch Gladbach, 2010.

[2] Mike McCarthy, Helen Fagerlind, Ines Heinig, Tobias Langner, Stefanie Heinrich, Lisa Sulzberger, Swen Schaub: ASSESS D1.1 - Preliminary Test Scenarios. Crowthorne, 2009.

[3] Marcus Wisch, Helen Fagerlind, Mike McCarthy, Mathieu Roynard, Wesley Hulshof, Jean-Francois Boissou, Swen Schaub, Ines Heinig, Matias Viström: ASSESS D1.2 - Specifications for Scenario Definitions. Bergisch Gladbach, 2010.

[4] Marcus Wisch, Helen Fagerlind, Mike McCarthy, Mathieu Roynard, Wesley Hulshof, Jean-Francois Boissou, Swen Schaub, Ines Heinig, Matias Viström: Analysis of accident data for test scenario definition in the ASSESS project. ESAR Conference,
Hannover 2010.

[5] Maminirina Ranovona, Jun Tsuchida, Estelle Chin, Thomas Unselt, Oscar Munoz, Andrés Aparicio: ASSESS D3.2 - Report on the experimental study results of the evaluation of behavioral aspects. Brussels, 2011.

[6] Jens Hoffmann: Das Darmstädter Verfahren (EVITA) zum Testen und Bewerten von Frontalkollisionsgegenmaßnahmen. Fortschrittsberichte VDI, Reihe 12, Band 693. Düsseldorf: VDI Verlag, 2008.

[7] Winner, Hermann: Frontalkollisionsschutzsysteme. In: Winner, Hakuli, Wolf (Hrsg.): Handbuch Fahrerassistenzsysteme, S. 522ff. 2. Auflage. Verlag Vieweg + Teubner, Wiesbaden 2012.

[8] Mages, Mark: Top-Down-Funktionsentwicklung eines Einbiege- und Kreuzenassistenten. Fortschrittsberichte VDI, Reihe 12, Band 694. Düsseldorf: VDI Verlag, 2009.

[9] Jörg Breuer, Andreas Faulhaber, Peter Frank, Stefan Gleissner: Real World Safety Benefits of Brake Assistance Systems. 20st. ESV Conference, Lyon 2007.

[10] Christhard Gelau, Tom Gasser, Andre Seeck: Fahrerassistenz und Verkehrssicherheit. In: Winner, Hakuli, Wolf (Hrsg.): Handbuch

Fahrerassistenzsysteme, S. 24ff. 2. Auflage. Verlag Vieweg + Teubner, Wiesbaden 2012.

[11] Schöner HP, Hurich W, Haaf D: Selbstfahrendes Soft Crash Target zur Erprobung von Fahrerassistenzsystemen. Konferenz AAET 2011, Braunschweig.

[12] Patrick Seiniger, Oliver Bartels, Marcus Wisch, Tobias Langner: Development of a Target Propulsion System for ASSESS. 22nd ESV Conference, Washington 2011.

[13] Carmen Rodarius, Patrick Seiniger, Sébastian Baurès, Kees Waagmeester, Andrés Aparicio, John Vissers, Maminirina Ranovona: ASSESS D4.3 Pre-crash Evaluation Final Status. Pub. pending.

[14] Lothar Henle, Uwe Regensburger, Bernd Danner, Elisabeth Hentschel, Carsten Hämmerling: Fahrerassistenzsysteme. ATZ Sonderheft "Die neue E-Klasse von Mercedes-Benz", 01/2009.

[15] Breuer, Jörg: Vorausschauende Längsschutzsysteme: Praxisrelevanz und Bewertungsverfahren. 14. VDA Technischer Kongress, Stuttgart 2012

[16] Patrick Seiniger, Oliver Bartels, Carmen Rodarius, John Vissers, Thomas Unselt, Andrés Aparicio, Sébastien Baurès: Ein validiertes Testverfahren für Notbremssysteme - Ergebnisse des ASSESS-Projekts. 5. Tagung Fahrerassistenz, München, 16.5.2012.

[17] Mark Mages, Martin Seyffert, Uwe Class: Benefit of Reversible Belt Pre-Pretensioning for Different Pre-Crash Scenarios - Reduction of Occupant Displacement and the Effect on Injury, Airbag 2010, Karlsruhe 2012 